\section{THE STRUCTURE OF ROFLAMYCOIN, A NEW POLYENE MACROLIDE ANTIFUNGAL ANTIBIOTIC}

Sir :

Roflamycoin (formerly named flavomycoin) is a pentaene macrolide antibiotic produced by Streptomyces roseoflavus ARAI 1951 var. jenensis nov. var. JA 5068 ${ }^{1}$. Its complete structure has been established as I (Fig. 1) on the basis of the partial structure formerly reported ${ }^{2,3}$ and of the examination by spectroscopic methods of degradation products obtained in specific chemical reactions.

The molecular weight of $\mathbf{I}, 738$, results from the ion $m / z 761(\mathrm{M}+\mathrm{Na})$ ! obtained by MS-FD. The molecular ion (M), $\pm m / z$ 1386, of the OTMS derivative of I obtained by MS-EI, together with a series of characteristic ions of the type (M$\mathrm{n} \times 90) \pm$ generated as a result of the elimination of consecutive trimethylsilanole molecules, indicated the presence in I of nine hydroxyl groups. The reduction of $\mathbf{I}$ with hydrogen on palladium catalyst yielded the product with the molecular weight 748 as determined by MS-FD on the basis of the ion $m / z 771(\mathrm{M}+\mathrm{Na})^{+}$. The formation of decahydroroflamycoin, II, points to the presence of five double bonds in the molecule of $\mathbf{I}$. The reaction of II with O-methyl hydroxylamine yielded methoxyiminodecahydroroflamycoin, III, as identified from the MS-FD ions: $m / z 778$ $(\mathrm{M}+\mathrm{H})^{ \pm}$and $m / z 800(\mathrm{M}+\mathrm{Na})+$. The formation of III indicates the presence in I of one keto group.

The carbon skeleton of roflamycoin and the position of oxygen functions were established on the basis of the mass spectral data obtained by MS-EI of the permethylated derivative, IV (Fig. 2), and of its trideuterio analogue, V (Fig. 2), obtained in the reactions sequence: 1. reduction of II with lithium aluminum hydride or lithium aluminum deuteride; 2 . methylation of the resultant products with methyl iodide in the presence of sodium hydride in tetrahydrofuran. Compounds IV and $\mathbf{V}$ exhibited molecular ions by MS-EI, $m / z 922$ and $m / z 925$, respectively. The fragment ions found in both mass spectra, resulting from the characteristic cleavage of $\mathrm{C}-\mathrm{C}$ bonds adjacent to heteroatoms of methoxy groups, enabled the location of the methoxy groups and deuterium atoms. The most important diagnostic ions, suggesting the structures of $\mathbf{I V}$ and $\mathbf{V}$,
Fig. 1. The structure of roflamycoin.

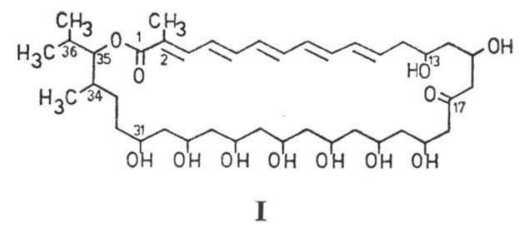

Fig. 2. The structure of compounds IV and $\mathbf{V}$.



are shown in Fig. 2. The presence in $\mathbf{V}$ of two deuterium atoms at $C_{1}$ and of one deuterium atom at $\mathrm{C}_{17}$ results from lithium aluminum hydride reduction of the lactone bond and of the keto group present in $\mathbf{I}$.

Similar to some other polyene macrolides ${ }^{4}$, a hemiketal structure in roflamycoin is formed upon the interaction of the keto group at $\mathrm{C}_{17}$ with one of the hydroxyl groups in $\delta$ position, at $\mathrm{C}_{13}$ or $\mathrm{C}_{21}$. The presence of the hemiketal structure in I was suggested by the ${ }^{13} \mathrm{C}$-NMR spectrum which contained an absorption at 97.1 ppm (in $\mathrm{d}_{0}$-DMSO) which is a singlet in the offresonance spectrum ${ }^{3)}$. According to a structural feature common for polyene macrolides with a hydroxyl group $\delta$ to the oxo function ${ }^{4}$ the formation of the hemiketal ring in $I$ between $C_{17}$ and $\mathrm{C}_{13}$ is most probable.

Due to the presence of the methyl group at $\mathrm{C}_{2}$ and the isopropyl group at $\mathrm{C}_{35}$ in $\mathrm{I}$, the lactone bond exhibits unusual stability for the polyene macrolide. Alkaline hydrolysis of the lactone bond in decahydroroflamycoin, II, requires much more drastic conditions than employed for other polyene macrolides. The reduction of II with lithium borohydride yields dodecahydroroflamycoin, VI, which contains a hydroxyl group at $\mathrm{C}_{17}$ as a result of the reduction of the ketone group without the simultaneous reduction of the lactone bond. This has been confirmed by the 
reduction of II with lithium-borodeuteride, yielding 17-deuterioundecahydroroflamycoin, VII. The resultant compounds, VI and VII, were analysed by MS-FD and, after their transformation to the volatile O-methyl derivatives, by MS-EI. The molecular ions obtained by MS-FD for VI and VII were $m / z 751(\mathrm{M}+\mathrm{H})^{+}, m / z 773(\mathrm{M}+$ $\mathrm{Na})^{\ddagger}$ and $m / z 752(\mathrm{M}+\mathrm{H})^{ \pm}, \mathrm{m} / z 774(\mathrm{M}+\mathrm{Na})^{+}$, respectively. The O-methyl derivatives of VI and VII exhibited by MS-EI the molecular ions at $m / z 890(\mathrm{M}) \div$ and $m / z 891(\mathrm{M}) \pm$.

The position of the lactone bond in $\mathbf{I}$ has been established by comparing the mass spectra of the $\mathrm{O}$-methyl derivatives of dodecahydroroflamycoin, VI, which contains an unreduced lactone bond, and of IV with the reduced lactone. Diagnostic for the location of the lactone bond between $C_{1}$ and $C_{35}$ is the presence only in the mass spectrum of IV of the ion at $m / z 87$. These results are in agreement with the previously reported data obtained from the ${ }^{1} \mathrm{H}-\mathrm{NMR}$ analysis of roflamycoin $^{2)}$.

Within the antibiotic groups of methyl pentaenes and carbonyl conjugated pentaenes $\mathbf{I}$ is the first representative in which a keto group was shown to be present. The molecule contains a large macrolide ring of 35 carbon atoms without the presence of a carboxyl group or an aminosugar. The novel structure is characterized by conjugation of a methyl pentaene with the lactone carbonyl group and by the presence of a hemiketal structure formed by a keto group. By these structural features roflamycoin is unambiguously distinguished from the other known carbonyl conjugated pentaenes, mycoticin ${ }^{5)}$ and flavofungin $^{6)}$.

\section{Acknowledgements}

The authors acknowledge the financial support of these studies by the Institute of Organic Chemistry, Polish Academy of Science, Warsaw. We also wish to thank Dr. G. ENGelHard from the Central Institute of Physical Chemistry, Academy of Science of GDR, Berlin-Adlershof, for ${ }^{13} \mathrm{C}-\mathrm{NMR}$ spectra.

\author{
R. SCHLEGEL \\ H. THRUM \\ Central Institute of Microbiology \\ and Experimental Therapy, Academy \\ of Sciences of GDR, Jena, GDR

\section{J. ZIELINSKI \\ E. BOROWSKI} \\ Department of Pharmaceutical Tech- \\ nology and Biochemistry, Technical \\ University, 80-952 Gdansk, Poland
}

(Received April 28, 1980)

\section{References}

1) Schlegel, R.; H. Thrum, G. Bradler \& R. FÜGNer: Flavomycoin, ein neues Polyenantibioticum aus Streptomyces roseoflavus. Produktion, Isolierung und Eigenschaften. Z. Allg. Mikrobiol. 11: 661 670, 1971

2) Schlegel, R. \& H. Thrum: A new polyene antibiotic, flavomycoin. Structural investigations I and II. J. Antibiotics 24: 360 374, 1971

3) Schlegel, R.; D. Tresselt, H. Thrum \& G. ENGelHardt: On the structure of flavomycoin, a polyene antibiotic of Streptomyces roseoflavus. Proc. of XIth Int. Symp. on Chem. of Nat. Prod. IUPAC, Golden Sands, Bulgaria, Abstr. Vol. 1, pp. 227 230, 1978

4) Pandey, R. C. \& K. L. Rinehart, Jr.: Polyene antibiotics. VII. Carbon-13 nuclear magnetic resonance evidence for cyclic hemiketals in the polyene antibiotics amphotericin $\mathrm{B}$, nystatin $\mathrm{A}_{1}$, tetrin $\mathrm{A}$, tetrin $\mathrm{B}$, lucensomycin, and pimaricin. J. Antibiotics 29: 1035 1042, 1976

5) Wasserman, H. H.; J. E. van Verth, D. J. MCCAUSTLAND, I. J. Borowitz \& B. Kamber: The mycoticins, polyene macrolides from Streptomyces ruber. J. Am. Chem. Soc. 89: 1535 1536, 1967

6) Bognar, R.; S. Makleit, K. Zsupan, B. O. Brown, W. J. S. Lockley, T. P. TOUbe \& B. C. L. Weedon: Flavofungin. J. Chem. Soc. Perkin I 1972: 1848 1856, 1972 